\title{
Analisis Preeklampsia Ibu Hamil pada Masa Pandemi Covid-19 di Puskesmas Sepatan Kabupaten Tangerang Tahun 2021
}

\author{
Yenny Aulya ${ }^{1}$, Vivi Silawati ${ }^{2}$,Wulan Safitri ${ }^{3}$ \\ 1,2,3 Prodi Kebidanan Fakultas Ilmu kesehatan, Universitas Nasional \\ Email: yenny.aulya@civitas.unas.ac.id
}

\begin{abstract}
Medical record data at the Sepatan Health Center in 2019 showed that the incidence of preeclampsia from 735 deliveries was obtained as many as 93 people (12.65\%) pregnant women who underwent examinations in the January-December 2020 period, and increased to 116 people (13.25\%) from 875. childbirth, and in January 2021 there were 35 preeclampsia of pregnant women and 81 preeclampsia of pregnant women, out of 875 deliveries. Analyzing factors associated with preeclampsia of pregnant women during the Covid-19 pandemic at the Sepatan Public Health Center, Tangerang Regency in 2021. Methods This type of research is an analytical survey research, with a cross sectional approach. This population is all pregnant women who experience preeclampsia in January 2021 as many as 35 respondents, using a total sampling technique of 35 respondent's pregnant women with preeclampsia. The results showed that five variables were statistically proven to have a significant relationship with the incidence of preeclampsia, namely age $(p=0.010<0.05)$, parity $(p=0.021<0.05)$, history of disease $(p=$ $0.004<0$, 05) multiple pregnancy $(p=0.026<0.05)$ and nutritional status $(p=0.007<0.05)$. There is a significant relationship between age, parity, history of disease, multiple pregnancies and nutritional status on the incidence of preeclampsia of pregnant women at the Puskesmas Sepatan, Tangerang District in 2021. For midwives to be more observant in examining preeclampsia, especially age (<20 years or $>35$ years), mothers who are pregnant for the first time, have a history of disease, pregnancy with multiple fetuses and nutritional status who are overweight in pregnant women
\end{abstract}

Keywords : pregnant women, preeclampsia

\begin{abstract}
Abstrak
Data rekam medis di Puskesmas Sepatan Tahun 2019 menunjukkan angka kejadian preeklampsia dari 735 persalinan didapatkan seanyak 93 orang $(12,65 \%)$ Ibu hamil yang melakukan pemeriksaan periode Januari-Desember 2020, dan mengalami peningkatan menjadi 116 orang $(13,25 \%)$ dari 875 persalinan, dan di bulan januari 2021 sebanyak 35 preeklampsia ibu hamil dan 81 preeklampsia ibu bersalin, dari 875 persalinan. Menganalisis fakor yang berhubungan dengan preeklampsia ibu hamil pada masa pandemi Covid-19 di Puskesmas Sepatan Kabupaten Tangerang Tahun 2021. Metode Jenis penelitian ini merupakan penelitian survey analitic, dengan pendekatan cross sectional. Populasi ini adalah semua ibu hamil yang mengalami preeklampsia pada bulan Januari 2021 sebanyak 35 responden, menggunakan teknik total sampling sebanyak rsponden 35 ibu hamil dengan preeklampsia. Hasil penelitian menunjukkan lima variabel yang terbukti secara statistic memiliki hubungan yang bermakna dengan kejadian preeklampsia yaitu umur $(\mathrm{p}=0,010<0,05)$, paritas $(\mathrm{p}=0,021<0,05)$ riwayat penyakit $(\mathrm{p}=0,004<0,05)$ kehamilan ganda $(\mathrm{p}=0,026<0,05)$ dan status gizi $(\mathrm{p}=0,007<0,05)$. Ada hubungan yang bermakna antara umur, paritas, riwayat penyakit, kehamilan ganda dan status gizi terhadap kejadian preeklampsia ibu hamil di Puskesmas Sepatan Kabupaten Tangerang Tahun 2021. Agar bidan lebih jeli dalam melakukan pemeriksaan preeklampsia terutama usia ( $<20$ tahun atau $>35$ tahun), ibu yang hamil untuk pertama kalinya, adanya riwayat penyakit, kehamilan dengan janin kembar dan status gizi yang mengalami kegemukan pada ibu hamil
\end{abstract}

Kata Kunci : ibu hamil, preeklampsia 


\section{PENDAHULUAN}

Menurut WHO angka kejadian preeklampsia tahun 2017 berkisar antara $0,51 \%-38,4 \%$. Di negara maju angka kejadian preeklampsia berkisar 6-7\% dan eklampsia $0,1-0,7 \%$, sedangkan angka kematian ibu yang diakibatkan preeklampsia dan eklampsia di negara berkembang masih tinggi. Preeklampsia salah satu sindrom yang dijumpai pada ibu hamil di atas 20 minggu terdiri dari hipertensi dan proteinuria dengan atau tanpa edema (Kemenkes RI, 2017).

Hasil studi pendahuluan yang telah dilakukan di bagian rekam medis Puskesmas Sepatan Kabupaten Tangerang didapatkan jumlah Ibu hamil yang melakukan pemeriksaan periode JanuariDesember 2019 sebanyak 735 orang dan yang mengalami preeklampsia sebanyak 93 orang $(12,65 \%)$ dan mengalami peningkatan di tahun 2020 menjadi 116 orang $(13,25 \%)$ dan di bulan januari 2021 sebanyak 35 preeklampsia ibu hamil dan 81 preeklampsia ibu bersalin, dari 875 persalinan. Data tersebut masih tetap tinggi setiap tahunnya sehingga perlu adanya kewaspadaan karena diketahui preeklampsia merupakan salah satu faktor risiko kesakitan dan kematian pada ibu dan janinnya. Ibu hamil yang mengalami preeklampsia memerlukan pengelolaan dan pemantauan yang ketat terhadap kondisinya dan janinnya sehingga penyakit tidak berkembang lebih berat agar tidak membahayakan jiwa ibu dan janin yang dikandungnya.

\section{METODE PENELITIAN}

Penelitian ini menggunakan metode survey analitic, yaitu survei atau penelitian yang mencoba menggali bagaimana dan mengapa fenomena kesehatan itu terjadi, dengan pendekatan cross sectional dimana data yang menyangkut variabel bebas atau risiko dan variabel terikat atau variabel akibat, akan dikumpulkan dalam waktu yang bersamaan (Notoatmodjo, 2015).

Populasi dalam penelitian ini adalah seluruh ibu hamil dengan preeklampsia di Puskesmas Sepatan Kabupaten Tangerang bulan januari tahun 2021 yaitu sebanyak 35 ibu hamil. Pengambilan sampel dalam penelitian ini adalah semua ibu hamil dengan preeklampsia berjumlah 35 orang di Puskesmas Sepatan Kabupaten Tangerang tahun 2021.

\section{HASIL DAN PEMBAHASAN}

Dapat diketahui bahwa dari 35 responden diketahui preeklampsia berat sebanyak 11 responden $(31,4 \%)$ dan preeklampsia ringan sebanyak 24 responden $(68,6 \%)$, umur tinggi $(<20$ th, $>35$ th) sebanyak 8 responden $(22,9 \%)$ dan umur rendah (20-35 th) sebanyak 27 responden $(77,1 \%), 14$ responden $(40,0 \%)$ dan paritas multipara sebanyak 21 responden $(60,0 \%)$, sebanyak 12 responden $(34,3 \%)$ dan tidak ada riwayat penyakit sebanyak 23 responden $(65,7 \%)$, kehamilan ganda (gemelli) sebanyak 9 responden $(25,7 \%)$ dan tidak kehamilan ganda (tunggal) sebanyak 26 responden $(74,3 \%)$, sebanyak 10 responden $(28,6 \%)$ dan status gizi baik (Bila LILA > 23,5 cm) sebanyak 25 responden $(71,4 \%)$.

Tabel 1.Analisis Univariat

\begin{tabular}{lll}
\hline Preeklampsia & f & \% \\
\hline Berat & 11 & 31,4 \\
Ringan & 24 & 68,6 \\
\hline Umur & f & \% \\
\hline Tinggi $(<20$ th, $>35$ th) & 8 & 22,9 \\
Rendah $(20-35$ th) & 27 & 77,1 \\
\hline Paritas & f & \% \\
\hline Primipara & 14 & 40,0 \\
Multipara & 21 & 60,0 \\
\hline Riwayat Penyakit & f & $\mathbf{\%}$ \\
\hline Ada & 12 & 34,3 \\
Tidak Ada & 23 & 65,7 \\
\hline
\end{tabular}




\begin{tabular}{lll}
\hline Kehamilan Ganda & f & \% \\
\hline Ya (Gemelli) & 9 & 25,7 \\
Tidak (Tunggal) & 26 & 74,3 \\
\hline
\end{tabular}

\begin{tabular}{lll}
\hline Status Gizi & f & \% \\
\hline Kurang & 10 & 28,6 \\
Baik & 25 & 71,4 \\
\hline
\end{tabular}

Tabel 2. Analisis Bivariat

\begin{tabular}{|c|c|c|c|c|c|c|c|}
\hline \multirow[t]{3}{*}{ Umur } & \multicolumn{4}{|c|}{ Preeklampsia } & \multicolumn{2}{|c|}{ Total } & \multirow[t]{2}{*}{$\mathrm{p}$ Value } \\
\hline & \multicolumn{2}{|c|}{ Berat } & \multicolumn{2}{|c|}{ Ringan } & & & \\
\hline & (n) & $(\%)$ & (n) & $(\%)$ & (n) & $(\%)$ & \\
\hline Tinggi & 6 & 75,0 & 2 & 25,0 & 8 & 100 & 0,010 \\
\hline Rendah & 5 & 18,5 & 22 & 81,5 & 27 & 100 & \\
\hline \multicolumn{8}{|l|}{ Paritas } \\
\hline Primipara & 8 & 57,1 & 6 & 42.9 & 14 & 100 & 0.021 \\
\hline Multipara & 3 & 14.3 & 18 & 85.7 & 21 & 100 & \\
\hline \multicolumn{8}{|l|}{ Riwayat Penyakit } \\
\hline Ada & 8 & 66.7 & 4 & 33,3 & 12 & 100 & 0,004 \\
\hline Tidak ada & 3 & 13 & 20 & 87,0 & 23 & 100 & \\
\hline \multicolumn{8}{|l|}{ Kehamilan Ganda } \\
\hline Ya (Gemelli) & 6 & 66,7 & 3 & 33,3 & 9 & 100 & 0,026 \\
\hline Tidak (Tunggal) & 5 & 19,2 & 21 & 80,8 & 26 & 100 & \\
\hline \multicolumn{8}{|l|}{ Status Gizi } \\
\hline Kurang & 7 & 70,0 & 3 & 30,0 & 10 & 100 & 0,007 \\
\hline Baik & 4 & 16,0 & 21 & 84,0 & 25 & 100 & \\
\hline Jumlah & 11 & 100 & 24 & 100 & 35 & 100 & \\
\hline
\end{tabular}

Pembahasan

Hubungan

Preeklampsia di Puskesmas Sepatan Kabupaten Tangerang Tahun 2021

Berdasarkan hasil penelitian, diketahui bahwa ada hubungan antara umur dengan preeklampsia ibu hamil pada masa Covid-19 di Puskesmas Sepatan Kabupaten Tangerang Tahun 2021, yang dibuktikan dengan nilai $\rho(0,010)<\alpha(0,05)$. Hasil uji Statistik juga diperoleh nilai OR sebesar $13.200 \approx 13,2$ artinya responden yang memiliki umur tinggi memiliki peluang sebanyak 13,2 kali mengalami preeklampsia ibu hamil. Dengan tingkat kepercayaan $95 \%$ diyakini bahwa nilai CI $(2,031-85,805)$.

Usia sangat mempengaruhi kehamilan maupun persalinan. Usia yang baik untuk hamil atau melahirkan 20 sampai 35 tahun.

Pada usia tersebut alat reproduksi wanita telah berkembang dan berfungsi secara maksimal. Sebaliknya pada wanita dengan usia di bawah 20 tahun atau diatas 35 tahun kurang baik untuk hamil maupun melahirkan, karenakehamilan pada usia ini memiliki resiko tinggi seperti terjadinya keguguran, atau kegagalan persalinan, bahkan bisa menyebabkan kematian. Wanita yang usianya lebih tua memiliki tingkat resiko komplikasi melahirkan lebih tinggi dibandingkan dengan yang lebih muda. Bagi wanita yang berusia 35 tahun keatas, selain fisik melemah, jugakemungkinan munculnya berbagai resiko gangguan kesehatan, seperti darah tinggi, diabetes dan berbagai penyakit lain (Gunawan S, 2010). 
Usia merupakan bagian dari status reproduksi yang penting. Umur berkaitan dengan peningkatan atau penurunan fungsi tubuh sehingga mempengaruhi status kesehatan seseorang. Usia yang baik untuk hamil adalah 20 sampai 35 tahun (Depkes RI, 2000). Royston dan Armstrong (1994) juga menyatakan bahwa wanita usia remaja yang hamil untuk pertama kali dan wanita yang hamil pada usia >35 tahu akan mempunyai resiko yang sangat tinggi untuk mengalami preeklampsia (Indriani, 2012).

Pada kehamilan $<20$ tahun, keadaan reproduksi yang belum siap untuk menerima kehamilan akan meningkatkan keracunan kehamilan dalam bentuk preeklampsia atau toksemia gravidarum. Sedangkan pada usia 35 tahun atau lebih akan terjadi perubahan pada jaringan dan alat reproduksi serta jalan lahir tidak lentur lagi. Pada usia tersebut cenderung didapatkan penyakit lain dalam tubuh ibu, salah satunya hipertensi dan preeklampsia (Manuaba, 2007).

Hasil penelitian ini sesuai dengan teori yaitu umur berisiko ( $<20$ tahun dan $>35$ tahun) lebih besar mengalami preeklampsia. Hal ini karena ibu hamil $<20$ tahun mudah mengalami kenaikan tekanan darah dan lebih cepat menimbulkan kejang. Sedangkan usia ibu $>35$ tahun seiring bertambahnya usia rentan untuk terjadinya peningkatan tekanan darah. Selain itu usia $<20$ tahun keadaan alat reproduksi belum siap untuk kehamilan. Rahim belum siap mampu untuk memberikan perlindungan kehamilan dan secara psikologis mental juga belum siap dan matang (Kurniasari D, et.al., 2015).

Hasil penelitian ini didukung dengan hasil penelitian (Saraswati 2016), didapatkan ada hubungan umur ibu dengan kejadian preeklampsia pada ibu hamil di RSUD Kabupaten Brebes tahun 2014 dengan $\mathrm{p}$ value0,0001. Penelitian yang dilakukan oleh (Situmorang 2016) juga menemukan ada hubungan umur ibu dengan kejadian preeklampsia pada ibu hamil di Poli KIA RSU Anutapura Palu tahun 2016 dengan $p$ value 0,000 .

Hasil penelitian ini sesuai dengan penelitian Nursal dkk (2015) yaitu terdapat hubungan yang kuat antara usia ibu dengan kejadian preeklampsia (p- value 0,006 OR 8,3 95\% CI 2,4-2,8). Penelitian ini juga sejalan dengan penelitian Ananth et al yang menunjukkan bahwa usia ibu berisiko berpeluang untuk preeklampsia. Hasil penelitian ini juga diperkuat dengan hasil penelitian yang dilakukan oleh Nuning dan Mardiana (2016) yang menyatakan bahwa ada hubungan antara umur dengan kejadian preeklampsia (p-value 0,0001 dan OR 15,731). Hasil analisis regresi logistik dalam penelitian ini menunjukkan bahwa usia ibu merupakan faktor nomor tiga yang paling dominan yang mempengaruhi kejadian preeklampsia pada ibu bersalin.

Penelitian ini sejalan dengan penelitian Bej et al yang menunjukkan bahwa usia berisiko berhubungan dan usia berisiko berpeluang 2,28 kali untuk preeklampsia. Ibu hamil yang berusia $<20$ tahun dan $>35$ tahun berisiko 4,886 kali berisiko untuk terkena preeklampsia dibandingkan dengan ibu hamil yang berusia 20-35 tahun. Hasil penelitian ini juga sejalan dengan penelitian Tessema et al (2015) yang menunjukkan bahwa wanita hamil berusia 35 tahun ke atas memiliki risiko 4 kali meningkatkan preeklampsia dibanding wanita hamil berusia 25-29 tahun.

Peneliti berpendapat bahwa, usia reproduksi sehat dikenal bahwa usia yang aman untuk kehamilan dan persalinan adalah usia 20-35 tahun. Menurut teori yang ada preeklampsia lebih sering didapatkan pada masa awal dan akhir usia reproduktif yaitu usia remaja atau di atas 35 tahun. Saat wanita bertambah tua, cenderung memiliki masalah kardiovaskuler dimana terjadi penurunan fungsi pembuluh kardiovaskuler yang berhubungan dengan penuaan pembuluh darah uterus dan arteri kaku. Selain itu, ketika hamil wanita yang semakin tua, 
maka adaptasi hemodinamik selama kehamilan menjadi lebih sulit. Oleh karena itu, apabila usia ibu saat hamil termasuk usia yang berisiko maka ibu harus melakukan pemeriksaan antenatal dan konseling kesehatan ke pelayanan kesehatan. Hal tersebut dilakukan untuk mencegah dan melakukan penanganan yang tepat apabila terjadi preeklampsia kehamilan.

\section{Hubungan Paritas Terhadap Preeklampsia Ibu Hamil di \\ Puskesmas Sepatan \\ Tangerang Tahun 2021}

Berdasarkan hasil penelitian, diketahui bahwa ada hubungan antara paritas dengan preeklampsia ibu hamil pada masa Covid-19 di Puskesmas Sepatan Kabupaten Tangerang Tahun 2021, yang dibuktikan dengan nilai $\rho(0,021)<\alpha$ $(0,05)$. Hasil uji Statistik juga diperoleh nilai OR sebesar $8.000 \approx 18$ artinya responden yang memiliki paritas primipara memiliki peluang sebanyak 8 kali mengalami preeklampsia ibu hamil. Dengan tingkat kepercayaan 95\% diyakini bahwa nilai CI $(1,588-40,299)$.

Paritas merupakan jumlah kehamilan yang menghasilkan janin yang lahir hidup, bukan jumlah janin yang dilahirkan (bobak, I ,2004). Paritas yang

aman adalah 1-3 jumlah anak. Apabila lebih dari 3 mempunyai angka kematian lebih tinggi paritas lebih tinggi kematian maternal.

Resiko pada paritas tinggi dapatd ikurangi atau dicegah dengan keluarga berencana (Prawirohardjo, 2002). Paritas adalah seorang wanita yang sudah pernah melahirkan bayi yang dapat hidup (Syaifuddin A, B, 2011). Pada primipara frekuensi preeklampsi lebih tinggi bila dibandingkan dengan multipara terutama pada primipara muda. Wanita yang telah banyak melahirkan $\geq 3$ orang rentan terhadap komplikasi yang serius, bahaya padamasa kehamilan salah satunya adalah preeklampsi dimana pada paritas yang tinggialiran darah akan menurun keplasenta yang menyebabkan ganguan plasenta sehingga terjadi gangguan pertumbuhan janin karena kekurangan oksigenasi (Prawirohardjo, 2008).

Paritas merupakan salah satu penyebab paling banyak ibu hamil mengalami preeklampsi. Semakin muda kehamilan seseorang (primipara) atau semaki banyak seseorang melahirkan (Grandemultipara) akan semakin besarpeluang ibu hamil tersebut mengalami preeklampsi. Hal ini diakibatkan oleh karena wanita hamil pertama dan dalam keadaan hamil dan berusia muda lebih cenderung rentan terhadap timbulnya preeklampsi yang diakibatkan oleh belum matangnya alat reproduksi untuk hamil sedangkan pada pada wanita yang telah berulang kali mengalami persalinan lebih diakibatkan karena kondisi tubuh dan kesehatannya yang menjadi lemah sehingga kemungkinan terkena preeklampsi lebih besar (Prawirohardjo, 2010)

Penelitian ini didukung oleh penelitian Resmi (2013), yang menyatakan bahwa ibu yang memiliki jumlah paritas berisiko sebesar 56,8\% pada kelompok kasus dan pada kelompok kontrol yaitu sebagian besar terjadi pada ibu yang jumlah paritas tidak berisko (2-3 kali) yaitu sebesar $55,3 \%$ dengan hasil uji statistik dengan uji chi-square menunjukan tidak terdapat hubungan yang signifikan antara paritas dengan kejadian preeklampsia $(\mathrm{P}$ value $=$ 0,076, OR=1,628). Hal ini juga sesuai dengan penelitian yang dilakukan oleh Trisnawati (2010) yang menyatakan paritas tidak mempunyai hubungan yang bermakna terhadap kejadian preeklampsia dengan hasil uji statistik $(\mathrm{p}=0.194>0.05)$ dengan nilai Odds Ratio1.34. Selain itu menurut penelitian Indriani (2012), menunjukan bahwa tidak adanya hubungan yang signifikan antara faktor paritas terhadap kejadiaan preeklampsia yaitu 0,325 .

Analisa peneliti bahwa dari hasil penelitian yang telah didapatkan dengan 
kejadian preeklampsi ringan lebih banyak pada ibu hamil dengan paritas tidak beresiko dibandingkan dengan ibu hamil yang beresiko. Paritas merupakan faktor predisposisi kejadian preeklampsi yang memiliki pengaruh. Hal ini sesuai teori yang diungkapkan bahwa paritas $>3$ merupakan salah satu faktor predisposisi dari preeklampsi (Prawirohardjo,2008).

Hubungan Riwayat Penyakit Terhadap Preeklampsia Ibu Hamil di Puskesmas Sepatan Kabupaten Tangerang Tahun 2021

Berdasarkan hasil penelitian, diketahui bahwa ada hubungan antara paritas dengan preeklampsia ibu hamil pada masa Covid-19 di Puskesmas Sepatan Kabupaten Tangerang Tahun 2021, yang dibuktikan dengan nilai $\rho(0,004)<\alpha$ $(0,05)$. Hasil uji Statistik juga diperoleh nilai OR sebesar $13.333 \approx 13,3$ artinya responden yang memiliki riwayat penyakit memiliki peluang sebanyak 13,3 kali mengalami preeklampsia ibu hamil. Dengan tingkat kepercayaan 95\% diyakini bahwa nilai CI $(2,419-73,483)$.

Status kesehatan wanita sebelum dan selama kehamilan adalah faktor penting yang mempengaruhi timbul dan berkembangnya komplikasi. Riwayat penyakit diabetes dan hipertensi merupakan salah faktor yang dihubungkan dengan preeklampsia (Djannah, 2010).

Hipertensi merupakan salah satu penyakit yang mengakibatkan kesakitan yang tinggi. Hipertensi atau penyakit darah tinggi adalah gangguan pada pembuluh darah yang mengakibatkan suplai oksigen dan nutrisi yang dibawa oleh darah terhambat sampai ke jaringan tubuh yang membutuhkannya. Secara umum, hipertensi merupakan suatu keadaan tanpa gejala, dimana tekanan darah yang tinggi di dalam arteri menyebabkan meningkatnya risiko terhadap penyakit-penyakit yang berhubungan dengan kardiovaskuler seperti stroke, gagal ginjal, serangan jantung, dan kerusakan ginjal (Widyaningrum, 2012).
Diabetes merupakan suatu penyakit dimana tubuh tidak menghasilkan insulin dalam jumlah yang cukup atau sebaliknya, tubuh kurang mampu menggunakan insulin secara maksimal (walaupun jumlah insulin sudah cukup), Insulin adalah hormone yang dihasilkan pankreas, yang berfungsi mensuplai glukosa dari darah ke sel-sel tubuh untuk dipergunakan sebagai bahan bakar tubuh. Kehamilan dapat mempengaruhi timbulnya penyakit diabetes pada seseorang. Sejak kehamilan terjadilah perubahan tingkat Diabetes merupakan suatu penyakit dimana tubuh tidak menghasilkan insulin dalam jumlah yang cukup atau sebaliknya, tubuh kurang mampu menggunakan insulin secara maksimal (walaupun jumlah insulin sudah cukup), Insulin adalah hormone yang dihasilkan pankreas, yang berfungsi mensuplai glukosa dari darah ke sel-sel tubuh untuk dipergunakan sebagai bahan bakar tubuh. Kehamilan dapat mempengaruhi timbulnya penyakit diabetes pada seseorang. Sejak kehamilan terjadilah perubahan tingkat karbohidrat dalam tubuh ibu yang diperlukan untuk energi lebih dari biasanya bagi pertumbuhan janin. Namun asupan karbohidrat yang meningkat dapat membuat hormone insulin dalam tubuh tidak mencukupi. Peran hormone ini yaitu untuk mengendalikan kadar gula dalam darah yang diubah dari karbohidrat. Akibatnya terjadilah penimbunan kadar gula yang menyebabkan kenaikan kadar gula darah. Diabetes bawaan maupun diabetes yang didapat selama hamil bisa berakibat buruk bagi kehamilan dan berisko terjadinya preeklampsia (Inchtiari: 2005, Puspitasari:2009)

Hal ini sesuai dengan penelitian yang dilakukan oleh Novia Lusiana (2014), bahwa ada hubungan yang signifikan antara riwayat penyakit yang lalu dengan kejadian preeklampsia $(\mathrm{p}=0,000)$. Penelitian ini sesuai dengan teori yang dikemukakan Fadlun (2011), preeklampsia pada hipertensi kronik yaitu preeklampsia yang 
terjadi pada perempuan hamil yang telah menderita hipertensi sebelum hamil. Varney (2006) menyatakan bahwa seorang wanita yang mempunyai riwayat penyakit yang parah akan lebih membahayakan kondisi dirinya sendiri pada saat hamil. Maka dari itu ibu hamil yang mempunyai riwayat penyakit pada saat hamil mempunyai resiko lebih besar mengalami preeklampsia dibandingkan dengan ibu yang tidak mempunyai riwayat penyakit

Penelitian ini didukung oleh hasil penelitian Puspitasari (2009) yang menunjukan bahwa dari hasil analisis uji statistik menggunakan uji chi square dan perhitungan nilai $O R$ dengan derajat kepercayaan (CI) 95\% dapat diketahui ada hubungan yang signifikan antara kejadian ibu yang memiliki riwayat hipertensi dengan kejadian preeklampsia pada ibu hamil $(\mathrm{p}=0,013)$. Nilai OR- 4,125 $(\mathrm{CI}=1,432-11,881)$ menunjukan bahwa ibu hamil yang mengalami hipertensi sebelum kehamilannya mempunyai risiko 4,125 kali lebih besar untuk mengalami kejadian preeklampsia dibandingkan dengan ibu yang sebelum kehamilannya tidak mengalami kejadian hipertensi.

Menurut teori, preeklampsia cenderung terjadi pada wanita yang memiliki riwayat penyakit dalam hal ini menderita diabetes melitus karena diabetes merupakan penyakit yang dapat menjadi faktor pencetus terjadinya preeklampsia. Penyakit diabetes melitus hampir 50\% yang terjadi pada wanita hamil berkembang menjadi preeklampsia. Hal ini terjadi karena saat hamil, plasenta berperan untuk memenuhi semua kebutuhan janin. Preeklampsia terjadi pada ibu dengan diabetes melitus karena adanya peningkatan produksi deoksikortikosteron (DOC) yang dihasilkan dari progesterone di darah plasma dan meningkat tajam selama trimester ketiga. Hipertensi sering dijumpai dari wanita diabetes dengan penyakit ginjal sehingga berisiko tinggi mengalami preeklampsia (Kurniasari D, et.al., 2015).
Penelitian ini sejalan dengan penelitian Nursal dkk (2015) yang menunjukkan bahwa riwayat penyakit diabetes mellitus berhubungan dengan kejadian preeklampsia dan bukan merupakan faktor preeklampsia ( $\mathrm{p}$-value 0,003).

Selain itu, hasil penelitian juga sama dengan hasil penelitian Rozikhan (2007) yang menunjukkan ada hubungan signifikan antara ibu yang mempunyai diabetes melitus dengan preeklampsia ( $\mathrm{p}$-value 0,03). Tetapi bila dilihat OR nya dapat disimpulkan bahwa ibu hamil yang mengalami diabetes melitus mempunyai peluang 18,46 kali untuk terkena preeklampsia dibanding dengan ibu yang tidak ada diabetes mellitus 1,35.

4.2.2.4 Hubungan Kehamilan Ganda Terhadap Preeklampsia Ibu Hamil di Puskesmas Sepatan Kabupaten Tangerang Tahun 2021

Berdasarkan hasil penelitian, diketahui bahwa ada hubungan antara kehamilan ganda dengan preeklampsia ibu hamil pada masa Covid-19 di Puskesmas Sepatan Kabupaten Tangerang Tahun 2021, yang dibuktikan dengan nilai $\rho(0,026)<\alpha$ $(0,05)$. Hasil uji Statistik juga diperoleh nilai OR sebesar $8.400 \approx 8,4$ artinya responden yang memiliki kehamilan ganda (Gemelli) memiliki peluang sebanyak 8,4 kali mengalami preeklampsia ibu hamil. Dengan tingkat kepercayaan $95 \%$ diyakini bahwa nilai CI (1,543- 45,737).

Mengacu hasil penelitian yang telah dilakukan sejalan dengan teori yang ada dimana wanita dengan kehamilan kembar berisiko tinggi mengalami preeklampsia hal ini biasanya disebabkan oleh peningkatan massa plasenta danproduksi hormon (Varney, dkk. 2007)

Kehamilan ganda atau kehamilan kembar adalah kehamilan dengan dua janin atau lebih. Kehamilan kembar adalah satu kehamilan dengan dua janin. Kehamilan kembar dapat memberikan resiko yang lebih tinggi terhadap bayi dan ibu. 
Pertumbuhan janin ganda lebih sering mengalami gangguan dibandingkan janin tunggal seperti kejadian preeklamsia akibat adanya beban penambahan sirkulasi darah kejanin (Purwanto, 2009).

Sejalan dengan penelitian yang dilakukan oleh Atikasari (2009) yang berjudul faktor-faktor yang berhubungan dengan preeklamsia pada ibu hamil di rumah sakit Islam Sultan Agung Semarang. Hasil penelitiannya didapatkan nilai pvalue $=0,016$ sehingga ada hubungan kehamilan ganda dengan kejadian preeklamsia. Dari hasil penelitian ini masih rendahnya kehamilan ganda pada ibu hamil di rumah sakit Islam Sultan Agung. Dengan nilai $\mathrm{OR}=4.66$ yaitu ibu yang memiliki kehamilan ganda mempunyai peluang 4.66 kali mengalami preeklampsia.

Peneliti berasumsi bahwa faktor resiko kejadian preeklamsi adalah riwayat tekanan darah tinggi yang kronis sebelum kehamilan, riwayat mengalami preeklamsia sebelumnya, riwayat preeklamsia pada ibu atau saudara perempuan, kegemukan, dan mengandung lebih dari satu orang bayi. Oleh karena ibu kehamilan kembar merupakan penyebab terjadinya preeklamsi. Dalam penelitian ini adanya faktor risiko kehamilan ganda dengan kejadian preeklamsi hal ini disebabkan karena masih tiingginya kehamilan ganda pada ibu bersalin.

\section{Hubungan Status Gizi Terhadap Preeklampsia Ibu Hamil di Puskesmas Sepatan Kabupaten Tangerang Tahun 2021}

Berdasarkan hasil penelitian, diketahui bahwa ada hubungan antara status gizi dengan preeklampsia ibu hamil pada masa Covid-19 di Puskesmas Sepatan Kabupaten Tangerang Tahun 2020, yang dibuktikan dengan nilai $\rho(0,007)<\alpha$ $(0,05)$. Hasil uji Statistik juga diperoleh nilai OR sebesar $12.250 \approx 12,3$ artinya responden yang memiliki status gizi kurang memiliki peluang sebanyak 12,3 kali mengalami preeklampsia ibu hamil. Dengan tingkat kepercayaan 95\% diyakini bahwa nilai CI $(2,185-68,692)$

Gizi adalah makanan yang dapat memenuhi kesehatan. Zat gizi adalah unsur yang terdapat dalam makanan dan dapat mempengaruhi kesehatan. Gizi adalah suatu proses organisme menggunakan makanan yang dikonsumsi secara normal melalui proses digesti, absorpsi, transportasi, penyimpanan, metabolisme dan pengeluaran zat-zat yang tidak digunakan untuk mempertahankan kehidupan, pertumbuhan dan fungsi normal dari organorgan serta menghasilkan energi (Waryana, 2010)

Menurut teori, Status gizi adalah ekspresi dari keadaan keseimbangan dalam bentuk variabel tertentu atau perwujudan dari nutriture dalam bentuk variabel tertentu (Sibagariang, 2010). Gizi yang kurang akan menyebabkan pertumbuhan janin terganggu baik secara langsung maupun oleh nutrisi yang kurang ataupun tidak langsung akibat fungsi plasenta terganggu. Dengan demikian akan terjadi kompetisi antara ibu, janin dan plasenta untuk mendapatkan nutrisi dan hal ini akan berpengaruh terhadap pertumbuhan plasenta serta janin yang akan berdampak pada berat lahir bayi dan berat plasenta (Surinati, 2011).

Hasil penelitian ini sesuai dengan penelitian Wulandari (2016) yang berjudul hubungan jarak kehamilan dan status gizi dengan kejadian preeklampsia pada ibu hamil di RS Aura Syifa Kabupaten Kediri Tahun 2015 yang menyatakan bahwa ada hubungan jarak kehamilan dan status gizi dengan kejadian preeklampsia. Demikian pula penelitian Andriani dkk (2016) yang berjudul hubungan IMT dengan kejadian preeklampsia di RSUP Dr. M. Djamil Padang. Hasil penelitian menyatakan ada hubungan IMT dengan kejadian preeklampsia dengan kejadian preeklampsia. Penulis berpendapat, penyebab terjadinya preeklamsi bisa disebabkan oleh status gizi. Berdasarkan status gizi kategorinya yaitu normal 
$23,5 \mathrm{~cm}-25 \mathrm{~cm}$ dan tidak normal kategori gemuk/ obesitas $>25 \mathrm{~cm}$. Asupan gizi yang cukup pada ibu hamil akan menentukan kesehatan ibu hamil dan janin yang dikandungnya. Bila ibu mengalami kekurangan gizi selama hamil akan menimbulkan masalah, baik pada ibu maupun pada janin

\section{SIMPULAN}

Sebagian besar preeklampsia ibu hamil memiliki umur rendah sebanyak 27 orang $(77.1 \%)$, paritas multipara sebanyak 21 orang $(60.0 \%)$, tidak ada riwayat penyakit sebanyak 23 orang $(65.7 \%)$, tidak kehamilan ganda sebanyak 26 orang (74,3\%), dan status gizi baik sebanyak 25 orang $(71.4 \%)$ di Puskesmas Sepatan Kabupaten Tangerang Tahun 2021. Ada hubungan yang bermakna antara umur, paritas, riwayat penyakit, kehamilan ganda dan status gizi terhadap preeklampsia ibu hamil pada masa covid-19 di Puskesmas Sepatan Kabupaten Tangerang Tahun 2021. Riwayat penyakit memiliki nilai OR tertinggi yang memiliki peluang terbesar sebanyak 13,333 kali dalam preeklampsia ibu hamil jika.

\section{SARAN}

Berdasar hasil penelitian, disarankan agar bidan lebih jeli dalam melakukan antisipasi preeklampsia terutama usia <20 tahun atau $>35$ tahun, ibu yang hamil untuk pertama kalinya, adanya riwayat penyakit, kehamilan dengan janin kembar dan status gizi yang mengalami kegemukan pada ibu hamil. Bidan disarankan agar memotivasi ibu hamil untuk pemeriksaan antenatal care secara rutin, pemeriksaan tekanan darah secara rutin, lebih meningkatkan kualitas pelayanan kesehatan antenatal care pada ibu hamil, dan menggiatkan penyuluhan dan konseling informasi dan edukasi (KIE) tentang risiko tinggi kehamilan.

\section{DAFTAR PUSTAKA}

Alisjahbana A, et.al.,(2011) Report on the
Achievement of Millenium Development Goals in Indonesia 2011. 2011;124.

Bobak, I, (2004), Keperwatan Maternitas.Jakarta : EGC.

Badan Pusat Statistik, Badan Koordinasi Keluarga Berencanan Nasional, Departemen Kesehatan, Macro International (2013). Survei Demografi dan Kesehatan Indonesia 2012. SDKI. 2013;16.

Cunningham, F Gary, Dkk. (2009), ObstetriWilliams Edisi 1 Dan 2. Jakarta : EGC.

(2013)Obstetri William Ed.23 Vol 2. Jakarta: EGC; 2013.

de Souza Rugolo LMS, Bentlin MR, Trindade CEP. Preeclampsia: Effect on the Fetus and Newborn. Neoreviews [Internet]. 2011;12(4):e198-206.

Availablefrom:http://neoreviews.aap publications.org/lookup/doi/10.1542 /n eo.12-4-e198

Grum T, et.al. (2017), Determinants of preeclampsia / Eclampsia among women attending delivery Services in Selected Public Hospitals of Addis Ababa , Ethiopia: a case control study. 2017;1-7.

Junia (2020), Faktor Resiko Ibu Hamil Pada Kejadian Preeklampsia, Skripsi, Unair, 2020

Kemenkes RI (2015), Kesehatan dalam Kerangka Sustainable Development Goals (SDGs). Rakorpop Kementeri Kesehat RI. 2015;(97):24. Available from:http://www.pusat2.litbang.dep kes.go.id/pusat2_v1/wpcontent/uplo ads/2015/12/SDGs-Ditjen BGKIA.pdf

Kemenkes RI. Pedoman Pelayanan Antenatal Terpadu. Kementrian Kesehatan, Direktur JendralBina Kesehatan Masyarakat.2010; 1 of 40.Availablefrom:http://www.keseh atanibu.depkes.go.id/wp 
content/uploads/downloads/2013/12 /Pedoman-ANC-Terpadu.pdf

Kemenkes RI. Profil Kesehatan Indonesia. Vol. 70, Kesehatan. 2016. 1780$1790 \mathrm{p}$.

Kurniasari D (2015), Arifandini F. Hubungan Usia , Paritas Dan Diabetes Mellitus Pada Kehamilan Dengan Kejadian Preeklamsia Pada Ibu Hamil Di Wilayah Kerja Puskesmas Rumbia Kabupaten Lampung Tengah Tahun 2014. J Kesehatan Holistik. 2015;9(3):14250.

Meriza, (2010), Hubungan Umur Dan ParitasIbu Bersalin Dengan Kejadian Pre-Eklampsia Di Rsup Dr. M. Djamil Padang: Akademi Kebinana AlifahPadang.

Noatmojdo Soekidjo,

2012.MetedologiPenelitian

Kesehatan Edisi Revisi.Jakarta : Rineka Cipta.

Nursal, et.al., (2015), Faktor Risiko Kejadian Preeklampsia pada Ibu Hamil di RSUP DR. M. Djamil Padang Tahun 2014.

Osungbade KO, Ige OK. Public Health Perspectives of Preeclampsia in Developing Countries: Implication for Health System Strengthening. J Pregnancy.2011;2011:1-6.

Availablefrom:http://www.hindawi. com/journals/jp/2011/481095/

Prawirohardjo, (2010).Ilmu Kebidanan. Jakarta: Yayasan Bina Pustaka (2014). Ilmu Kebidanan. Jakarta : PT. Bina Pustaka Sarwono Prawirohardjo.

Saifuddin A. (2009). Ilmu Kebidanan. Jakarta: PT Bina Pustaka Sarwono
Prawiroharjo.

Sibagariang, E. E. (2010). Gizi Dalam Kesehatan Reproduksi. Jakarta: CV. Trans Info Media.

Sugiyono. (2015). Metode Penelitian Administrasi. edisi 2015. Bandung : Alfabeta

Surinati, I. D. A. K. (2011). Perbedaan Berat Badan Lahir Dan Berat Plasenta Lahir Pada Ibu Hamil Aterm Dengan Anemia Dan Tidak Anemia Di RSUD Wagaya Kota Denpasar Tahun 2011. Tesis. Denpasar

Sukriani, (2013). Hubungan Usia Dan ParitasIbu Bersalin Dengan Kejadian Pre-Eklampsia Di Rsup Dr. M. DjamilPadang: Akademi Kebidanan Alifah Padang

Uzan J,et.al., (2011). Pre-eclampsia: Pathophysiology, diagnosis, and management. Vasc Health Risk Manag. ;7(1):467-74.

Wahyuni, (2014). Hubungan Umur Dan ParitasIbu Bersalin Dengan Kejadian Pre-Eklampsia Dirumah Sakit Tk. III Dr.Reksodiwiryo: Akademi KebidananAlifah Padang Waryana. (2010), Gizi Reproduksi. Yogyakarta: Pustaka Rihama

Winkjosastro, H, (2006). Ilmu Kebidanan.Jakarta YBPSP.

WHO (2007), World Health Statistics 2007. World Health Statistics. 2007. 1-97 p.

Yunirman, (2013), Gambaran Umur Dan Paritas Ibu Bersalin Dengan KejadianPre-Eklampsia Rsup Dr. M. Djamil Padang: Akademi Kebidanan Amanah Padang. 